\title{
Ensayo de fundamentación filosófica del concepto de "fraternidad" propuesto en la Fratelli tutti
}

\author{
JOSÉ JOAQUíN CASTELLÓN-MARTIN* \\ Facultad de Teología San Isidoro de Sevilla (España) \\ jcastellonm64@gmail.com
}

\begin{abstract}
Resumen
El concepto de fraternidad, tal y como se propone en la Fratelli Tutti, se vería privado de su potencial descriptivo y crítico si se entendiera como una mera opción sentimental de la persona. En este artículo se busca profundizar en su virtualidad ética desde la experiencia cristiana concretada en Pablo de Tarso, afianzando la dignidad humana, mostrando la diferencia con el camino de la excelencia aristocrática de los clásicos; pretende, así mismo, mostrar cómo las reflexiones metafísicas de Zubiri y Levinas desvelan el fundamento fraternal de nuestra dignidad, y la exigencia de justicia y solidaridad que nos constituye.
\end{abstract}

Palabras Clave: fraternidad, otro, dignidad, san Pablo, Zubiri, Levinas.

\section{Essay on the philosophical foundation of the concept of "fraternity" proposed in the Fratelli tutti}

\begin{abstract}
The concept of fraternity, as proposed in the Fratelli Tutti, would be deprived of its descriptive and critical potential if it were understood as a mere sentimental option of the person. This article seeks to deepen its ethical virtuality from the Christian experience concretized in Paul of Tarsus, strengthening the buman dignity, showing the difference with the path of aristocratic excellence of the classics; it also aims to show how the metaphysical reflections of Zubiri and Levinas reveal the fraternal foundation of our dignity, and the condition for justice and solidarity that constitutes us.
\end{abstract}

Key words: fraternity, other, dignity, saint Paul, Zubiri, Levinas.

\footnotetext{
* $\quad$ Sacerdote desde 1990, ha tenido responsabilidades de párroco, en la pastoral social de la diócesis de Sevilla y en cooperación con diócesis de China. Licenciado en Filosofía por la Universidad de Sevilla 1989; doctor en Filosofía por la Universidad de Sevilla 2001; licenciado en ciencias eclesiásticas por el Centro de Estudios Teológico de Sevilla 2005. Libros: Ellacuría y la Filosofía de la Praxis (2003). Últimos artículos: Apuntes de ética de la liberación desde Ignacio Ellacuría" (2014); "Horizonte racional de la doctrina social del papa Francisco" (2015); "Una proyección política de la realidad moral" (2017); "Técnicas de envilecimiento: Una reflexión desde el pensamiento de Gabriel Marcel" (2020).
} 
Este ensayo quiere profundizar en la realidad de la vinculación de las personas entre sí, de manera que hace que podamos decir que la persona es constitutivamente fraterna; no solo que está llamada moralmente a la fraternidad, sino que sin atender a esa llamada no puede vivir con verdad en su propia realidad. La realidad del otro, tal y como se aquilató en la filosofía del siglo XX, puede comprenderse desde el concepto de fraternidad; y desde esta conceptualización trataremos de sacar a la luz, más claramente, sus repercusiones morales y sociales. En este ensayo, el otro se va a configurar como el hermano, como aquel que me constituye en la fraternidad y me llama a la fraternidad. La encíclica Fratelli tutti del papa Francisco avanza, desde esta misma clave de comprensión, en el desarrollo de la doctrina social de la Iglesia, y de las consecuencias en moral social y política de la fe. Este trabajo quiere mostrar un camino de fundamentación racional de la intuición de la encíclica: todos somos hermanos. Una intuición que es profunda convicción de la fe cristiana y fundamento pre-político de la vida social y comunitaria.

\section{CONCEPCIÓN DE LA FRATERNIDAD HUMANA EN LA FRATELLI TUTTI}

La encíclica Fratelli Tutti el papa Francisco hace una reinterpretación, radicalmente fiel a la tradición eclesial, del concepto de fraternidad, y la ofrece para colaborar con la reflexión común que necesita nuestro mundo; propone la fraternidad como piedra de toque de nuestra propia humanidad. Su reflexión está enmarcada por crisis civilizatorias tan importantes como la crisis financiera del 2008 y la pandemia del 2019, que han puesto de manifiesto las lagunas intrínsecas a las ideologías del capitalismo financiero y de los nacionalismos de cortas miras. A pesar de que la pretensión de la encíclica no es "resumir la doctrina sobre el amor fraterno, sino detenerse en su dimensión universal, en su apertura a todos." (Francisco, 2020: n. 6), muestra con detenimiento "el primado que se da a la relación, al encuentro con el misterio sagrado del otro, a la comunión universal con la humanidad entera como vocación de todos" (Francisco, 2020: n. 277) en el pensamiento cristiano y la acción de la Iglesia.

El papa Francisco denuncia que "en el mundo de hoy persisten numerosas formas de injusticia, nutridas por visiones antropológicas reductivas y por un modelo económico basado en las ganancias, que no duda en explotar, descartar e incluso matar al hombre" (Francisco, 2020: n. 22). Por la vía de los hechos y avalados por concepciones de la persona se dan situaciones en las que "la persona humana, creada a imagen y semejanza de Dios, queda privada de la libertad, mercantilizada, reducida a ser propiedad de otro, con la fuerza, el engaño o la constricción física o 
psicológica; es tratada como un medio y no como un fin" (Francisco, 2020: n. 24).

La encíclica asume dos maneras con las que la historia de la filosofía se ha acercado a la realidad de lo personal: la de la naturaleza humana (Francisco, 2020: n. 213), con raíces en la metafísica aristotélico-tomista, y la de la llamada o la vocación, con fundamento en la fenomenología dialógica que comienza su desarrollo en el siglo XX (Scheler, Stein, Buber, Levinas, Marcel, Mounier o Dussel). El lenguaje, con mucho, más usado en la encíclica es el lenguaje de la llamada, la vocación, el encuentro y la convocación (por ejemplo: Francisco, 2020: nn. 26, 41, 66, 81, 78, 93, 183 o 277$)$.

Para la tradición cristiana hay una llamada intrínseca en cada miembro de la familia humana al encuentro con el otro; "el mismo proyecto de fraternidad, inscrito en la vocación de la familia humana" (Francisco, 2020: n. 26). Una llamada que ha de sobreponerse incluso al natural instinto de conservación, que nos lleva a considerar a los diferentes como ajenos, incluso como un peligro. El instinto natural de autodefensa puede impulsarnos a rechazar al diferente; pero las personas y los pueblos solo son fecundos si saben integrar creativamente en su interior la apertura a los otros (véase Francisco, 2020: n. 41). La vocación a vivir en fraternidad con todos los hombres se hace presente de manera especial en la realidad del otro que sufre, en el que escuchamos la voz de Dios. La interpelación teologal desde el sufrimiento de los pobres está presente en toda la revelación cristiana, desde el relato de Caín y Abel, hasta la parábola del Buen Samaritano.

En el relato de sabor mítico de Caín y Abel, Dios pregunta a Caín: “¿Dónde está tu hermano Abel?” (Gn 4,9), al que había asesinado por envidia. Esta pregunta hace consciente a Caín de la dignidad de Abel, de su propia dignidad, y que estaba llamado a vivir la fraternidad: "Al preguntar, Dios cuestiona todo tipo de determinismo o fatalismo que pretenda justificar la indiferencia como única respuesta posible. Nos habilita, por el contrario, a crear una cultura diferente que nos oriente a superar las enemistades y a cuidarnos unos a otros" (Francisco, 2020: n. 57). De la misma manera, la parábola del Buen Samaritano, una parábola neotestamentaria sin referencias religiosas explícitas, plantea la pregunta definitiva para nuestra humanidad: " $¿ C o n$ quién te identificas? Esta pregunta es cruda, directa y determinante. ¿A cuál de [los personajes de la parábola] te pareces?" (Francisco, 2020: n. 64). Es la interrogación, escuchada como interpelación absoluta en el fondo de nuestra realidad, la que nos fuerza a responder a ese "llamado escrito como ley fundamental de nuestro ser" (Francisco, 2020: n. 66). Nuestra humanidad está radicalmente "ligada a la de los demás" (Francisco, 2020: n. 66). Nuestra propia 
dignidad humana se decide en la escucha a la llamada de lo Absoluto en el sufrimiento de los pobres: "Bajar de nuestra serenidad para alterarnos por el sufrimiento humano. Eso es dignidad" (Francisco, 2020: n. 68). Para la tradición cristiana "hemos sido hechos para la plenitud que sólo se alcanza en el amor" (Francisco, 2020: n. 68). Optar por vivir en este amor hacia el débil es optar por hacernos pueblo. Para el papa Francisco el concepto de "pueblo" como el de "humanidad" no tiene solo un valor descriptivo, sino también valorativo (Francisco, 2020: n. 77). Como muchas veces se ha dicho el proceso de humanización supone, pero no coincide con el de mera hominización.

Otro hecho que la parábola de que pensar es que la verdadera fraternidad se realiza en la superación de los límites familiares y culturales. No solo nacemos hermanos unos de otros, hemos de hacernos hermanos desde nuestra propia libertad: "El samaritano fue quien se hizo prójimo del judío herido. Para volverse cercano y presente, atravesó todas las barreras culturales e históricas. La conclusión de Jesús es un pedido: «Tienes que ir y hacer lo mismo» (Lc 10,37)" (Francisco, 2020: n. 81). El hombre herido al borde del camino "era un nadie, no pertenecía a una agrupación que se considerara destacable, no tenía función alguna en la construcción de la historia" (Francisco, 2020: n. 101), y, sin embargo, despertó en quien también estaba excluido del pueblo de Dios, un gesto de verdadera humanidad. La parábola nos muestra que, para acoger la realidad de nuestra propia humanidad, hemos de recorrer el camino de la superación de nuestros propios límites sociales y culturales. Hay en cada uno de nosotros "una ley de éxtasis: salir de sí mismo para hallar en otro un crecimiento de su ser" (Francisco, 2020: n. 88).

Como fundamento de esta fraternidad esencial, el papa Francisco propone explícitamente la dimensión religiosa: "Si no existe una verdad trascendente, tampoco existe ningún principio seguro que garantice relaciones justas entre los hombres: los intereses de clase, grupo o nación, los contraponen inevitablemente unos a otros" (Francisco, 2020: n. 273; Juan Pablo II, 1991: n. 44). Es difícil que la incondicionalidad de la dignidad y la fraternidad humanas pueda fundarse desde una instancia tan condicionada, biológica, personal, cultural e históricamente, como la razón humana. Francisco apunta con sencillez el origen de sus propias convicciones: "Otros beben de otras fuentes. Para nosotros, ese manantial de dignidad humana y de fraternidad está en el Evangelio de Jesucristo" (Francisco, 2020: n. 277).

En este breve recorrido por el concepto de fraternidad que aporta la encíclica han surgido temas de reflexión filosófica muy importantes: la esencia fraterna de la condición humana, la constitución de la humanidad de la persona desde la interpelación del otro débil y sufriente, la necesi- 
dad de trascender nuestros límites culturales para vivir humanamente, la interpelación trascendente que se nos plantea en la inmanencia de quien sufre. Como se puede constatar a primera vista, temas todos de profundo calado filosófico.

La dignidad de la persona se afirmó en el comienzo de la historia de la filosofía desde la excelencia del comportamiento y desde la perfección del ser que vamos modelando con nuestro esfuerzo moral. Es decir, se definió desde un dinamismo de perfección moral auto-céntrico. Para Platón, Aristóteles, los estoicos o los neoplatónicos, el hombre encuentra su dignificación en la luz de la propia racionalidad, en la identificación de nuestra razón con la Razón. Fundar la dignidad en la excelencia imposibilita acoger la fraternidad como elemento esencial de toda persona. Este límite teórico vino a romperse con la experiencia cristiana en la que la piedra de toque de nuestra vida está en nuestro comportamiento ante el hermano, y en la que cada persona independientemente de sus cualidades es hija de Dios. Esta intuición, presente en todo el Nuevo Testamento, es Pablo de Tarso quien la desarrolla más explícitamente; es en sus escritos donde se ha perfilado con más nitidez conceptual y teórica esta novedad del cristianismo. Al desarrollo de estas ideas dedicaremos los parágrafos: "De la moral de la virtud a la moral de la adhesión personal", "La salvación por la fe o el dinamismo del encuentro con el otro" y "La obligación que brota del otro en debilidad". Acabado este acercamiento más intuitivo que sistemático a la idea de que somos "con", "desde" y "gracias" al otro, que descubrimos como hermano y como origen de nuestra humanidad, acudiremos a dos filósofos del siglo XX para aquilatar el concepto de fraternidad: Zubiri y Levinás. Ninguno de los dos nombró este dinamismo personal como fraternidad, pero en ellos podemos encontrar la raíces antropológicas y metafísicas de la fraternidad. Sus filosofías se muestran complementarias. Desde Zubiri veremos cómo los otros constituyen nuestra realidad; y, desde Levinas, cómo acoger la llamada del otro conforma nuestra propia subjetividad.

\section{DE LA MORAL DE LA VIRTUD A LA MORAL DE LA ADHESIÓN PERSONAL}

Pablo de Tarso ha sido uno de los activistas y teóricos revolucionarios más grandes del que nos ha dejado constancia la historia. Su actividad evangelizadora y pastoral colaboró grandemente a que aquella nueva secta judía, a la que comenzaron a llamar "cristianos" (Hch 11,26), tuviera un crecimiento tan importante que en unas cuantas generaciones llega- 
ra a ser la religión oficial del imperio (Stark, 2009). Fue el emperador Teodosio en el año 380, en el decreto Cunctos populos, quien declaró a la religión cristiana, en la interpretación del Concilio de Nicea (325), como religión oficial del imperio romano. Los escritos de san Pablo tienen tanta fuerza y originalidad que aun hoy siguen inspirando y despertando polémica. Su experiencia de encuentro con Jesucristo fue tan poderosa que le hizo cambiar sus esquemas de comprensión religiosa y moral: comprendió que la elección de Israel no otorgaba a los judíos una posición privilegiada ante la salvación.

Desde hace unas décadas se han dado una gran variedad de interpretaciones en los estudios paulinos; algunas se separan de la interpretación tradicional lutero-agustiniana y proponen un horizonte de comprensión en el que san Pablo abre en su soteriología cristológica lo nacional judío a lo universal católico. En concreto nos referimos a la nueva Perspectiva en la interpretación de los escritos paulinos (Sanders, Dunn, Wright, etc.) (Pereira Delgado, 2021). Esta reflexión asume la línea de interpretación tradicional, sin caer en la interpretación unilateral que puede derivar de ciertas lecturas luteranas. Así asumimos la interpretación de que Dios ha enviado a su Hijo al mundo para que todos, judíos y gentiles, fueran justificados por la fe en él, "salvados por la fe en la persona de Jesús" (Alvarez-Cineira, 2016: 48-92).

Esta conmoción religioso-espiritual alcanza, como no podía ser de otra manera, a la comprensión de la moral de la persona. La experiencia del cristianismo marca un punto de inflexión en la cultura occidental, y se tardarán veinte siglos en asumir filosóficamente algunos de los interrogantes que trae consigo. Tanto la metafísica medieval y la moderna comienzan a asumir la novedad que el cristianismo imprimió en la concepción del hombre, del mundo y de la propia razón. El primer filósofo que asume el reto de pensar la experiencia cristiana ensanchando las categorías greco-latinas sería san Agustín (Heimsoheth, 1990: 19). En el siglo $\mathrm{XX}$, la necesidad de asumir racionalmente la experiencia creyente ante el cruel nihilismo nazi, seguirá retando a los filósofos y dando frutos teóricos de gran alcance, tanto en filósofos de tradición judía como cristiana.

Según el autor de los Hechos de los Apóstoles, Pablo era un hombre culto, formado en la mejor tradición judía, discípulo de Gamaliel (Hch 22,3) y conocedor de la Torá. Pero también adquirió un conocimiento significativo de la filosofía de su tiempo, estuvo enseñando durante dos años en la escuela filosófica de Tirano, en Éfeso (Hch 19,9), probablemente una escuela estoica, que eran las más abundantes en Asia Menor. Así, en Hch 17,18-34, Pablo parece citar escritos estoicos. Pudiera ser a Epiménides de Cnosos, filósofo y poeta del siglo VI a.C., en la frase "porque en el vivimos, y nos movemos"; y también a Cleantes (siglo IV 
a.C.), quien en su himno a Zeus se expresa en forma similar: "somos también su linaje", o quizás a Arato que tiene un verso parecido (Guevara-Pereda, 2017: 215). San Pablo, aunque no tiene una actitud de oposición a la filosofía, señala la insuficiencia de todo conocimiento humano para ser fundamento verdadero de la vida y hacernos vivir la plenitud (Ef 3,17-19); no va a recusar las concreciones de la moral filosófica, especialmente la estoica, sino su pretensión de justificar la vida de la persona, de acceder a su último fundamento, que no es ningún tipo de conocimiento, sino en encuentro con el Otro.

La moral propuesta por los filósofos griegos y romanos es una moral de la virtud. Podía entenderse la virtud como aquellos comportamientos que permiten a la persona vivir conforme al bien, al estilo aristotélico; podía entenderse, al estilo estoico, como el bien mismo de la persona ya que es su participación en el Logos-Alma del mundo. De cualquiera de estas dos formas la moral se entiende como esfuerzo personal por alcanzar la mayor perfección humana. Aristóteles esbozaba la perfección del hombre con el ideal del hombre magnánimo, un varón admirable en todo, y consciente de su perfección:

El magnánimo parecer ser el hombre que se siente digno de las cosas más grandes, y lo es en efecto (...) Es necesario que el hombre verdaderamente magnánimo esté lleno de virtud; y cuanto hay de grande en las virtudes de cada género debe poseerlo. Jamás estará bien en el magnánimo temblar o huir, así como nunca se rebajará a hacer daño (...) No manifestará en los triunfos una alegría excesiva; ni en los reveses un exceso de abatimiento (...) El magnánimo da más que recibe (...) También es propio del magnánimo no recurrir a nadie, o por lo menos hacerlo con desgana (...) Y mostrarse benévolo para con los de mediana condición (...) Jamás se le oirá quejarse, ni descender a pedir suplicante la cosas que le hagan falta (...) Tal es, pues, el magnánimo. (Aristóteles, 2008: 135-140)

De distinto tenor, mucho más matizado y con mucha más profundidad antropológica y existencial, pero en un mismo horizonte vital, Séneca dibuja a su amigo y discípulo, el joven Lucilio, el perfil del sabio en una serie de cartas en las que lo exhorta a la perfección moral. Una perfección cuya cúspide está en la autosuficiencia:

El sabio delimitará todo bien en su interior y dirá lo que dijo aquel Estilpón. A él, en efecto, estando sometida su patria, perdidos los hijos, perdida su esposa, mientras escapaba del incendio total solo y, pese a todo, feliz, Demetrio, le preguntaba si había perdido alguna cosa, a lo cual respondió: "Todos mis bienes están conmigo”. ¡He ahí al hombre fuerte y valeroso! Superó la propia victoria del enemigo. Dijo: "Nada he perdido"; obligó a 
aquél a dudar de su victoria. "Todos mis bienes están conmigo": justicia, valor, prudencia, la misma disposición a no considerar como un bien nada que se nos pueda arrebatar. (Séneca, 1986: 89)

El horizonte de perfección, tanto el del hombre magnánimo aristotélico, como el sabio sereno y autosuficiente de Séneca, perfila la dignidad humana desde una excelencia personal, que no es accesible a todos. La moral griega es una moral aristocrática. Es cierto que para Séneca la condición social de una persona no define sus actitudes personales; un esclavo puede estar más cerca de la sabiduría que muchos patricios romanos, y por ello deben ser tratados como personas, con justicia y con bondad (Séneca, 1986: 113-119). Pero su moral, incluso desde el cosmopolitismo estoico, sigue siendo para una élite, si bien definida por las capacidades y el esfuerzo. Como dice E. Gilson (2004: 314), la moral antigua buscaba modelar lenta y pacientemente la estatua interior para conseguir su perfección. La perspectiva moral que plantea la filosofía clásica es la de la configuración de la propia persona: hay bien y mal porque no todo aprovecha, y porque no todo nos encamina hacia el ideal de persona al que debemos tender. Como decía también san Pablo a los de Corinto: "Todo nos está permitido, pero no todo aprovecha" (1 Cor 10,23). Las virtudes morales son dinamismos de excelencia personal.

En este camino de la perfección moral nos encontramos con limitaciones, con dificultades, incluso con límites infranqueables. En uno de los muchos destellos de perspicacia y lucidez del filósofo cordobés, apunta los severos límites de la moral de la virtud que él mismo propone, y reconoce a su amigo y discípulo Lucilio que sus consejos sobre la salud del alma son como los que puede dar un enfermo a su compañero de habitación de hospital; consejos de quien ha probado varios remedios y recomienda aquellos que en algo le aliviaron: "No soy tan cínico como para realizar curaciones estando enfermo; mas como si me hallase en la misma enfermería converso contigo sobre la dolencia común a ambos y te expongo los remedios." (Séneca 1986: 90-93) Reconocía Séneca que queremos vivir desde un ideal de vida que no somos capaces de asumir. Como también decía san Pablo: "El bien que quiero no lo hago, y el mal que no quiero es, precisamente, lo que hago" (Rom 7,19). Este realismo antropológico y moral tan loable tanto en Séneca como en Pablo cuestiona la pretensión de que el último fundamento de nuestra humanidad sea la excelencia personal.

El peso inexorable del pasado en nuestro presente es un freno, a veces insalvable, en ese camino deseado de dignificación. Con la experiencia que da la edad no solo vamos aprendiendo que no todo lo que deseamos es posible, sino que alguna de las mejores posibilidades que 
teníamos en nuestra vida se frustraron sin remedio, bien por nuestra propia responsabilidad, bien por las circunstancias que se rodearon. Lo peor de nosotros mismos nos marcó en algún momento de nuestra vida. Así le ocurrió a Pablo de Tarso que aprobó el asesinato de discípulos de Cristo (Hch 7,58; 9,1-2), y desde ese momento fue para siempre aquel que persiguió a cristianos (1 Cor 15,9; Gál 1,13-14; Fil 3,6). Por eso, querer asumir el reto de nuestra libertad desde un ideal de perfección, nos lleva a una frustración constante. Si la perfección moral fuera el horizonte en el que se define nuestra libertad estaríamos condenados, como el Sísifo de Camus, a iniciar una vez y otra la tarea de poner sobre nuestros hombros débiles una carga que nos supera, y que, por eso, nos esclaviza.

Al final de ese largo esfuerzo, medido por el espacio sin cielo y el tiempo sin profundidad, se alcanza la meta. Sísifo ve entonces cómo la piedra desciende en algunos instantes hacia ese mundo inferior desde el que habrá de volver a subirla hasta las cimas, y baja de nuevo a la llanura. Sísifo me interesa durante ese regreso, esa pausa. Un rostro que sufre tan cerca de las piedras es ya él mismo piedra. Veo a ese hombre volver a bajar con paso lento, pero igual hacia el tormento cuyo fin no conocerá jamás. Esta hora que es como una respiración y que vuelve tan seguramente como su desdicha, es la hora de la conciencia. En cada uno de los instantes en que abandona las cimas y se hunde poco a poco en las guaridas de los dioses, es superior a su destino. Es más fuerte que su roca”. (Camus, 1985: 60)

El acto de suprema dignidad humana sería el inicio del camino de vuelta en busca de aquella piedra, para iniciar una ascensión que sabemos tan imposible como necesario intentar una y mil veces. La moral sería la condena que se nos impone por el delito de ser libres.

San Pablo afronta la cuestión de qué es lo que nos salva como personas, y su respuesta no va a estar en consonancia ni con quien situaba la dignidad personal en la adquisición de virtudes, ni en quien la sitúa en la pertenencia a un grupo étnico y en el cumplimiento de sus normas religiosas. Él señala que la experiencia de salvación, a pesar de nuestros límites personales y los de nuestra cultura, se nos ofrece en la adhesión por fe a una persona, a Jesucristo Crucificado (1Cor 1,24), la salvación nos viene del Otro.

3. LA SALVACIÓN POR LA FE O EL DINAMISMO DEL ENCUENTRO CON EL Otro

La carta que san Pablo dirige a los cristianos de Roma es uno de sus escritos con más calado reflexivo. Tiene, así mismo, un fuerte compo- 
nente contracultural, que plantea interrogantes, incluso, a la cultura de nuestros días. Su tono reflexivo y dialéctico se debe, en parte, a que $\mathrm{Pa}$ blo no escribe a una comunidad que él ha fundado, de la que conociera virtudes y defectos concretos. Por lo cual elabora una teología crítica con la cultura de su tiempo. La comunidad de Roma tiene características que vienen definidas por el contexto social en el que viven, la capital del Imperio. En ella hay ciudadanos romanos y otros de origen judío; así pues, san Pablo escribe a cristianos, judíos y gentiles, que han de vivir la fe en un ambiente cosmopolita, plural y disipado.

En la Roma imperial la ley política era considerada fundamento de la sociedad. Una ley que consagraba el poder de los aristócratas y los militares, y que se fundaba en un esquema económico esclavista e imperialista. La ley era en Roma el poder; y se definía desde el poder militar, el económico y, también, desde la capacidad de hablar convincentemente en el Senado; por eso la sociedad romana del siglo I daba una gran importancia a la oratoria y la filosofía. Heredadas de Atenas, la oratoria y la argumentación filosófica se habían convertido en eficaces armas políticas. Las armas, el dinero y la oratoria eran los resortes del poder de una sociedad cuyo valor sumo era el honor, pegamento social que cohesionaba todas las estructuras del imperio (Lendon, 1997). Por otro lado, aunque la mayoría de los cristianos de Roma eran de origen gentil, entre ellos también había familias de origen judío, que habían vivido y crecido cumpliendo la Torá de Moisés, algunos en la interpretación legalista de los fariseos, y todos con el sentimiento de superioridad que les daba el ser miembros del pueblo elegido (Vidal 2007: 197). Por ello, las polémicas con los creyentes que querían seguir observando los preceptos de la ley judía aparecen también en la carta a los Romanos; incluso es en ella donde con una mayor profusión de argumentos se rebate la manera legalista o de orgullo nacionalista al afrontar la religión y la vida. (Bornkamm, 1979: 176). Así pues, los cristianos de Roma, algunos de ellos judíos, y otros ciudadanos romanos, saben tanto de la ley religiosa judía como de la ley civil romana: "Hablo a quien sabe de leyes" (Rom 7,1) les dice san Pablo; son personas que han crecido valorando la ley, y sabiendo lo importante que es para la supervivencia de una institución social y de la sociedad misma; pero a la vez, han experimentado las limitaciones de vivir guiados por una ley civil, muchas veces injusta, y una ley religiosa que, vivida en el legalismo, se convierte en algo imposible de cumplir, o que experimentada como privilegio nacional desemboca en desprecio por el otro. Como el mismo apóstol sentenciará: "la ley produce la cólera” (Rom 4,15).

San Pablo en Romanos centra su evangelio (Rom 2,16) en la superación de una religiosidad definida por el orgullo de la observancia de las obras de la ley. Y propone que solo nos salva la comunión con la perso- 
na de Jesucristo (Vanni, 2006: 9-13). La ley entendida como afirmación nacionalista, margina y enfrenta; la ley vivida como criterio exclusivo de nuestra dignidad, nos condena. San Pablo había sido fiel cumplidor de la ley, hasta tal punto de fanatismo que había encabezado una persecución contra los discípulos de Jesús. Había experimentado, en sí mismo, que vivir desde unos criterios de dignidad externos llevaba a los peores vicios: al orgullo nacionalista y religioso, y al fratricidio. Su experiencia de encuentro con Jesucristo (Hch 9,1-18) lo cambia por completo. "Esta transformación de todo su ser no fue fruto de un proceso psicológico, de una maduración o evolución intelectual y moral, sino que llegó desde fuera: no fue fruto de su pensamiento, sino del encuentro con Jesucristo." (Benedicto XVI, 2008) La salvación no es fruto de nuestro esfuerzo, sino del encuentro con el Señor, con el Otro: "Ahora, independientemente de la ley, la justicia de Dios se ha manifestado, justicia de Dios por la fe en Jesucristo, para todos los que creen y son justificados por el don de su gracia" (Rom 3,21-24). El criterio de valoración que Dios nos ha dado es Cristo y su entrega gratuita por nosotros, no ninguna norma abstracta y extrínseca. Y el fundamento de nuestra dignidad personal es la gracia de Dios, no nuestras virtudes; es Dios quien "justifica al que cree en Jesús" (Rom 3,26), su Hijo Crucificado.

La ley que rechaza Pablo como fuente de salvación es la Torá de Moisés, no una ley moral o política. Así mismo, la salvación de la que habla no es solo la salvación inmanente de vivir digna y felizmente en este mundo; es también la salvación trascendente. Su reflexión es de ámbito religioso. Pero san Pablo apunta que esta ley, que se les concedió conocer a los judíos por revelación, también la pueden conocer los gentiles desde su razón y conciencia, ya que los gentiles al cumplirla muestran que "tienen escrita en sus corazones la exigencia de la ley" (Rom 2,15). Por tanto, lo que dice de una ley de origen religioso, tiene también vigencia para la ley moral que procede de la razón. Por eso, se puede afirmar que Pablo de Tarso es el primer pensador que trasciende el esquema de la autorreferencialidad moral como horizonte ético fundamental. En vez de esa referencia a la propia realidad, propone la presencia del otro en nuestra vida como constituyente de nuestra libertad. Su reflexión cuestiona toda reflexión que busque apoyar la dignidad de la persona exclusivamente en sí misma. La dignidad nos es ofrecida por un Otro, que nos llama como hermano.

Mostrando la falsedad de la pretensión de que el último fundamento de la moral de la persona sea la propia virtud personal, Pablo comienza por desmentir que haya quien pueda vanagloriarse de su propia vida: 
Tanto judíos como griegos están bajo el pecado, como dice la Escritura: "No hay quien sea justo, ni siquiera uno solo. No hay un sensato, no hay quien busque a Dios. Todos se desviaron, a una se corrompieron; no hay quien obre el bien, no hay siquiera uno. Sepulcro abierto es su garganta, con su lengua urden engaños. Veneno de áspides bajo sus labios; maldición y amargura rebosa su boca. Ligeros sus pies para derramar sangre; ruina y miseria son sus caminos. El camino de la paz no lo conocieron, no hay temor de Dios ante sus ojos" (Rom 3,9-18).

La experiencia del pecado es universal; hombres y mujeres, judíos y gentiles experimentamos su poder y cómo nos esclaviza íntimamente a todos. Los condicionantes de nuestra libertad son tan fuertes que nadie por sí mismo puede escapar de la experiencia de la deshumanización. Unas veces pueden ser traumas de nuestro pasado; otras veces una cultura que nos hace compartir mentiras que engendran injusticia (Rom 1,18). Quien no reconoce su propia debilidad, no solo como algo del pasado, sino como instancia permanente, se engaña. La manipulación social puede hacer pasar por valor moral lo que no es más que interés de grupos concretos de poder. No hacía falta esperar a los maestros de la sospecha para poner en tela de juicio la conciencia moral cristalizada en normatividad religiosa. San Pablo se da cuenta de que la propia ley mosaica, a pesar de su origen divino, puede asumirse manipuladoramente, y ser fuente de pecado.

Cuando estábamos en la carne, las pasiones pecaminosas, excitadas por la ley, obraban en nuestros miembros, a fin de que produjéramos frutos de muerte. Yo no conocí el pecado sino por la ley. De suerte que yo hubiera ignorado la concupiscencia si la ley no dijera: ¡No te des a la concupiscencia! Mas el pecado, tomando ocasión por medio del precepto, suscitó en mi toda suerte de concupiscencias; pues sin ley el pecado estaba muerto. Porque el pecado, tomando ocasión por medio del precepto, me sedujo, y por él, me mató. (Rom 7,6-15).

La intuición de san Pablo es incisiva. La ley nos muestra el horizonte de perfección en nuestra vida, pero no nos ofrece ni la motivación adecuada, ni la fuerza necesaria para asumirlo. Por eso, en la mera afirmación de la ley, vivimos también la primera insinuación del mal y del pecado. Si la cumplimos, vivimos añorando los gozos perdidos; si no la cumplimos, vivimos avergonzados por nuestra debilidad. Desde el horizonte de la ley, nuestra virtud estará siempre ensombrecida por la afirmación orgullosa de uno mismo y el menosprecio a los demás, y por la envidia soterrada del gozo ajeno. 
Esta intuición de Pablo no conlleva que se anule el dinamismo de la búsqueda de la dignidad de nuestro comportamiento. Este dinamismo moral es intrínseco a la realidad de la persona. De hecho, en varias ocasiones en la misma carta a los Romanos, se afirma la vigencia de la ley: "¿Privamos a la ley de su valor? ¡De ningún modo! Más bien, la consolidamos" (Rom 3,31). "¿Qué decir, entonces? ¿Que la ley es pecado? ¡De ningún modo!” (Rom 7,7). La intuición de san Pablo no conlleva anular el dinamismo moral de la virtud, sino que subraya la prioridad axiológica y metafísica del dinamismo, más árquico y fontal, del Otro como origen de nuestra humanidad y dignidad personal.

La salvación gracias al Otro, que acabamos de señalar, se complementa en san Pablo con la salvación con el otro, cercano y hermano. Estoy refiriéndome a la noción de cuerpo con que el apóstol describe a la comunidad de los creyentes. Solo con los otros y en los otros podemos acoger la salvación del Otro que a todos nos regala la vida. Frente al cuerpo de pecado que es el individual: "yo, hombre miserable, ¿quién me librará de este cuerpo de muerte?” (Rom 7,24), san Pablo propone un cuerpo en el que somos salvados, que no es individual ni se afirma al margen de los otros, es un cuerpo con, en y para los otros: "Así como nuestro cuerpo, en su unidad, posee muchos miembros, y no desempeñan todos los miembros la misma función, así también nosotros, siendo muchos, no formamos más que un solo cuerpo en Cristo, siendo cada uno por su parte los unos miembros de los otros" (Rom 12,4-5). Es decir, "que Pablo no entiende cuerpo y corporeidad como algo que está en el hombre a la manera de la antigua fórmula griega (órfica) del cuerpo como tumba (soma/sema) y cárcel del alma. Cuerpo, para Pablo, es el hombre en su concreta realidad. El hombre no tiene un cuerpo, sino que es cuerpo" (Bornkamm 1979: 172) El cuerpo se caracteriza por que nunca se pertenece a sí mismo, sino que está sometido a una fuerza que lo mueve, ya se trate de la del pecado, que lo conduce al individualismo y a la muerte, o la del Señor para llegar a la vida (1 Cor 6,13.15ss.) (Bornkamm 1979: 173) Esta unión "no se vive en el campo abstracto de las ideas, sino en una experiencia profunda que cada individuo tiene de estar unido a Dios y que al compartirla cada una de ellas, crea una unidad entre los que participan de esta experiencia" (Fernández Ramos, 1999: 214). El individuo al trascender su individualidad se hace persona con los otros y por el Otro. Para Pablo, la comunidad cristiana no es como si fuera el cuerpo de Cristo, de una manera metafórica; la comunidad de los creyentes conforma realmente el cuerpo de Cristo en la historia, y esta comprensión teologal, que está en el núcleo mismo de la tradición cristiana, viene a completar la primera intuición de que nuestra salvación no la conseguimos en un esfuerzo individual por la perfección: es Otro 
quien nos salva, pero nos salva con los otros y en los otros, haciéndonos vivir, como Cristo mismo, para los otros.

Desde esta experiencia teologal de que somos uno en Cristo, Pablo se abre a la universalidad de la salvación, y a la relatividad de todo lo que nos distingue y separa: la raza, la cultura, el sexo, la condición social, ya que todos somos uno en Él: "Todos los bautizados en Cristo os habéis revestido de Cristo: ya no hay judío ni griego; ni esclavo ni libre; ni hombre ni mujer, ya que todos vosotros sois uno en Cristo Jesús" (Gal 3,2728). La experiencia de íntima solidaridad constitutiva en cada persona no se detiene en la facticidad del grupo humano en el que hemos nacido o crecido, sino que se abre a una catolicidad universal. Es la expresión religiosa de lo que la filosofía estoica comprendió desde la racionalidad en el concepto de ciudadanía universal; pero no concedida por virtud de la racionalidad, sino recibida como don para cada uno desde el otro. En definitiva, hay salida a la maldición de Sísifo, en el que nuestro esfuerzo por vivir conforme a una perfección inalcanzable nos deja en tristeza y frustración; y en el que, cuando pensamos conseguirlo, nos llenamos de orgullo y desprecio. Esta posibilidad se nos ofrece al ser acogidos por el otro, siendo esto el fundamento de nuestra libertad y de la propia dignidad.

La filosofía, naturalmente, no puede asumir una afirmación teológica sin más. El pensamiento teologal tiene que ser asumido por la filosofía como invitación a la reflexión. La filosofía dialógica y personalista del siglo XX ha profundizado en esa intuición religiosa, y ha hecho de ella el quicio desde el que iniciar una nueva reflexión ética y metafísica. La utopía de un mundo más fraterno, que nos propone Francisco en la Fratelli Tutti como horizonte social del evangelio, no tiene solo el aval religioso de la experiencia creyente, autores desde diversas perspectivas filosóficas han asumido esta realidad trascendental de comunión en la que somos personas. Pero antes de abordar esa perspectiva sistemática, es necesario que completemos el encuentro con el otro con la compasión con el otro que sufre.

\section{LA OBLIGACIÓN QUE BROTA DEL OTRO EN DEBILIDAD}

La presencia del otro en nuestra vida es amplia y multiforme: el otro cercano, familiar o amigo, el otro que nos atrae y nos enamora, el otro como enemigo, al que tememos o que nos repele. Pero en el ámbito de la fraternidad humana hay un elemento muy significativo para la reflexión, es el dato fenomenológico de la obligación ante el otro que sufre; que experimentamos en el nivel profundo de nuestra conciencia. 
Todos sentimos una íntima interpelación cuando nos encontramos con alguien que está sufriendo, incluso aun cuando esa interpelación se vea contrarrestada con otros sentimientos como la desconfianza, el miedo, la sospecha, el deseo de evitar problemas o la repugnancia. La interpelación del otro que sufre es un dato distinto a los demás. Cuando el otro es el que está en radical debilidad y, por eso mismo nos interpela, nos encontramos ante un hecho donde la obligación moral adquiere una dimensión propia. Como hemos visto, en la encíclica Fratelli Tutti, el papa Francisco, para profundizar en la necesidad de una sociedad más fraterna parte precisamente de esa experiencia, tal y como nos la encontramos en la parábola del Buen Samaritano (Lc 10,25-37). Y la eleva a la condición de categoría iluminadora de la moral y la política: "Esta parábola es un ícono iluminador, capaz de poner de manifiesto la opción de fondo que necesitamos tomar para reconstruir este mundo que nos duele. Ante tanto dolor, ante tanta herida, la única salida es ser como el buen samaritano" (Francisco, 2020: n. 67).

Esta experiencia de compasión ante el débil no puede conceptualizarse como mero sentimiento, aunque el sentimiento la acompañe. La profundidad con la que se enraíza en nosotros; la extensión y la duración con que se manifiesta; la importancia que tiene en nuestra vida tanto si respondemos a ella como si intentamos ignorarla; el horizonte que nos abre y al que nos fuerza a enfrentarnos; su presencia en todas las culturas; todo esto nos muestra que es una experiencia que abre una dimensión radical de la persona a asumir por la reflexión filosófica. Las reflexiones éticas que ignoran este dato de la obligación moral muestran la pobreza y el reduccionismo de los que adolecen. Ante los otros, y especialmente los otros que sufren, nos sentimos obligados a atenderlos y ayudarlos; esto es un hecho desde el que vivimos nuestra libertad personal; es un dato fenomenológico que requiere profundización para comprender cómo configura la moralidad humana.

Esa interpelación del otro en debilidad no se explica desde el dinamismo de auto-perfección que proponía la filosofía clásica, o desde la complacencia ante la propia benevolencia, que han propuesto emotivismos como el de Hume. Previo a cualquier ideal de persona que podamos proponernos, previo a la conciencia de lo que los demás piensen de nosotros, el grito de quien sufre se incrusta en nuestro ánimo con una fuerza que nos conmueve en lo más íntimo. A pesar de estar explicada en la tradición judeocristiana por la experiencia religiosa, esta experiencia de compasión con el que sufre podría decirse que posee una raíz diversa a la creencia explícita en un Dios Misericordioso. El sufrimiento del otro es un grito que el propio Dios tiene que escuchar; ya en la revelación bíblica, el grito del pobre tiene consistencia propia ante Dios. La sangre de- 
rramada del inocente Abel por su hermano Caín grita desde la tierra hasta llegar al cielo (Gen 4,10); el clamor del pueblo esclavizado llega a los oídos de Dios que se conmueve, y llama a Moisés para salvarlo (Ex 3,715). El sentimiento de compasión y de exigencia de justicia tiene la fuerza de interpelar al propio Dios. Hay una interpelación absoluta a nuestra realidad personal desde el inocente que sufre; incluso cuando la injusticia y sus sufrimientos hacen años que pasaron, y no podemos en absoluto hacer nada ante ello. Este sentimiento de obligación moral es una anomalía para todo relativismo moral y para el existencialismo nihilista, que está en su base.

En la tradición cristiana la llamada de Dios es, en muchas ocasiones, una llamada a sacar al pobre de su postración, y muestra la beligerancia de Dios contra quien lo oprime y explota. Esa fue la experiencia de muchos profetas que denunciaban las injusticias con los pobres: "Pisotean al pobre exigiéndoles parte de su cosecha" (Am 5,11); “oprimen a los débiles y aplastan a los necesitados" (Am 4,1); "juegan con la vida del pobre y del miserable por un poco de dinero o por un par de sandalias" (Am 8,5). En la Biblia, el pobre que sufre interpela, y suscita en el creyente la rebeldía contra la injusticia. El mandato de compasión ante el pobre encuentra su justificación no en razones humanas, sino en la misericordia de Dios: "Clamará a mí, y yo le oiré, porque soy compasivo" (Ex 22,26). Otros mandamientos encuentran un fundamento más humano, como el respeto al padre y a la madre: "para que se prolonguen tus días sobre la tierra que Yahveh, tu Dios, te va a dar" (Ex 20,12). El mandamiento de compasión con el pobre encuentra un fundamento teologal, en el ser y el actuar de Dios, lo mismo que los mandamientos referidos a la obligación de adorar a Dios, o la de respetar el descanso del sábado (Ex 20,5-11).

Este dinamismo de trascendencia personal, tal y como señalaba el papa Francisco en su encíclica, es el dinamismo fontal del que pende toda la estructura personal, el inicio de la experiencia de libertad y la moral humanas, y "nos revela una característica esencial del ser humano." (Francisco, 2020: n. 68) La autonomía de la razón ha de completarse con esta alteronomía que nos hace humanos.

\section{LOS OTROS CONSTITUYEN NUESTRA REALIDAD: ZUBIRI}

Que la exigencia de justicia y solidaridad está presente en todo código moral humano es una evidencia. En la mayor parte de los códigos morales antiguos, la solidaridad no se circunscribe exclusivamente a los miembros del propio clan o del propio pueblo, sino que se amplía con detalladas normas de hospitalidad. Hay autores que ven en estas normas de hospitalidad con el desconocido, con el rival incluso, el núcleo de la 
experiencia moral humana (Tomillo Noguero, 2010: 212-234). El profesor Rodríguez Duplá (2016: 108-110) ve en estas normas de hospitalidad una manifestación primera de una premisa fáctica del comportamiento humano, que en cada cultura se formula de diversas formas, pero que está a la base de toda experiencia ética; y lo considera refutación de la postura relativista. La interpelación moral del otro en debilidad no anula el peso de la crueldad y la indiferencia con las que muchas veces miramos el dolor de los pobres. Pero el sentimiento de compasión es una anomalía para la comprensión nihilista de la persona; y, como en las grandes revoluciones científicas del siglo XX, la anomalía puede convertirse en la piedra de angular de una nueva comprensión de la realidad. Sin la compasión, la persona deja de ser humana, en el sentido valorativo del término.

En esta reflexión les propongo la filosofía de Xavier Zubiri que aporta una visión orgánica del binomio "el yo y los otros". Para el pensador español el otro está presente en nuestra vida personal y en nuestra experiencia de libertad y, por tanto, en la dimensión moral mucho antes de que nuestra intencionalidad se centre en él, o que nuestros sentimientos se vean impactados por su realidad. No soy yo quien sitúa a los otros en el centro de mi vida. Ya están ahí en el mismo proceso de irme configurando como persona. La versión hacia los demás es algo real y físico, no meramente vivencial o intencional: "Los hombres estamos vertidos a los demás y son los demás hombres los que, en una o en otra forma, se han entreverado, y han intervenido, en mi vida. De aquí es de donde hay que partir" (Zubiri, 1986: 235).

El encuentro con los otros no viene de uno mismo, viene de los demás, y posibilita la mera supervivencia. Antes que nosotros podamos comprender que los demás pueden ayudarnos a sobrevivir, ellos ya están pendientes de todo lo que necesitamos. "Pero la propia situación biológica descrita va complicándose a través de la formalización, lo cual fuerza al niño a poner en juego su inteligencia, a hacerse cargo de la realidad. La tendencia a buscar la ayuda se convierte en algo bien determinado que temáticamente llamaremos socorro, una estructura formalmente emergente de la inteligencia sentiente" (Zubiri 1986, 236). De tal manera que es una entrega gratuita y sacrificada de los demás a cada uno de nosotros lo que nos ha permitido ser. Poner a la base de nuestra realidad personal la lucha de clases o la indiferencia ante los demás es fruto de una ideologización que olvida la realidad de nuestra vida.

La base biológica de la dimensión social, pronto, se ve asumida y superada. En esta relación de socorrencia nos encontramos con que los demás van conformando nuestra propia vida. Los otros, al permitirnos convivir con ellos, van configurando nuestra realidad, nuestra manera de 
ser y de vivir como personas. Vamos aprendiendo de los otros cómo ser personas: aprendemos su cultura, su lenguaje, su manera de moverse y de pensar, su manera de ser. Son los otros los que nos constituyen como seres humanos, nos entregan el sentido humano de la vida: la virtud y el pecado, la responsabilidad y la fiesta, el pudor y el erotismo, la cultura y la técnica, el humor y el amor... todo sentido de lo humano nos es dado. Por eso, no es que descubramos al otro como ajeno y queramos hacerlo próximo; es el otro el que nos constituye como seres humanos, el que nos entrega la humanidad en la concreción de la cultura, grupo social y la familia en el que hayamos nacido. Somos personas radical, inexcusable y físicamente siendo-con los otros. Esta condición es previa a toda opción moral, y la sustenta.

Se está "ya" con el otro y esto condiciona la propia conciencia. Pero no necesariamente en el sentido de que pensamos lo que piensan los otros o juzgamos lo que los otros juzgan; no en el sentido de que se nos impone desde fuera la obligación y el contenido de la obligación. Todo esto puede ocurrir, pero no es lo que debe ocurrir para completar nuestra conciencia total. Esta totalización de la conciencia es la que reclama que el otro está presente a la hora de constituirme como yo mismo. (Ellacuría, 1981: 48)

Antes de que seamos conscientes de nuestra propia realidad, antes de que decidamos actuar de una manera u otra, los otros ya han estado presentes en la constitución de la propia conciencia de nuestra realidad (Zubiri, 1986: 238). Intentar afirmarnos a nosotros mismos negando a los otros es un proyecto contradictorio. Somos seres constitutivamente sociales. Permanecer indiferentes a la realidad de los otros contradice una característica esencial del ser humano (Francisco, 2020: 68). El individualismo no nos hace más libres, ni más iguales, ni más hermanos, sino que contradice la esencia de nuestra propia realidad. "El individualismo radical es el virus más difícil de vencer. Engaña.” (Francisco, 2020: 105)

\section{LOS OTROS, FORMA DE NUESTRA SUBJETIVIDAD: LEVINAS}

En nuestro objetivo central de esclarecer la llamada del otro en necesidad como elemento esencial de la realidad humana, hemos acudido a la reflexión de Zubiri, que nos muestra que somos realmente ser-con-losotros; incluso, que sólo siendo para-los-otros podemos alcanzar una realización no contradictoria con nuestra propia realidad. Otro autor, también de la segunda mitad del siglo XX, nos ofrece una intuición complementaria: Emmanuel Levinas bucea en la constitución de nuestra subje- 
tividad, y en esa profundización encuentra también la primacía metafísica de los otros en nuestra libertad.

La persona se encuentra viviendo en un mundo en el que tiene que saber lo circundante para vivir, y tiene que saberse a sí mismo para poder encauzarse en él. Pero en medio de esos datos y objetivaciones entre las que nos movemos hay una experiencia fundante, muchas veces olvidada: subsistimos en esas realidades en las que nuestra vida consiste, podríamos decir interpretando a Levinas zubirianamente; somos radicalmente en medio de la configuración fáctica de nuestra persona. No solamente vivo a través de las cosas que tengo y soy, sino que subsisto ante todo eso y a través de todo eso, y porque subsisto en todo ello puedo ser libre (Castellón Martín, 2004: 257-279). Describir el todo, la totalidad de lo que hay, nunca da razón de la dimensión que sustenta la propia subjetividad; esa dimensión es nombrada como "Infinito". Cuando he descrito todo lo que hay e, incluso, todo lo que soy, aún no he dicho nada de la libertad que me hace ser yo.

Analizar lo que he llegado a ser, describir la objetivación del yo, definiría una filosofía que se queda en las ramas del árbol. Levinas quiere llegar a la raíz de la propia persona, y plantea que la puerta de entrada a la libertad que nos hace seres personales es la incoincidencia de la persona consigo misma. El Yo nunca es lo mismo, aunque siempre es el mismo. En todo momento de nuestra vida hemos de rechazar lo "ya vivido" para aventurarnos a conseguir nuestra propia identidad. El yo rechaza el sí, vivido como repugnancia, como hastío. Estos sentimientos son, según Levinas, manifestaciones de la conciencia de sí, y reposan en la no identidad entre el yo y el sí (Levinas, 1977: 61). El deseo de lo no dado, un tema tan clásico en la mística, es el primer paso de la reflexión metafísica.

Levinas nos habla provocativamente de una heterogeneidad radical entre la personalidad en la que consisto y el yo con el que subsisto. Esa heterogeneidad radical funda nuestra constitución como subjetividad abierta, es decir, como persona. Y la funda no de manera estática: todo lo constituido en nosotros es un yo que ya está en el pasado y del que sólo su negación me permitirá seguir viviendo como ser personal y libre. El yo es el eterno punto de partida. Ese punto de partida es constituido como tal por el deseo de lo que no soy. Esta heterogeneidad respecto a lo que soy solo puede venirnos por el afrontamiento del otro, irreductible a mis ideas y a mis propios deseos. El otro me permite entrar en una relación de libertad con mi propio ser, con el sí-mismo (Levinas, 1977: 60). Es el otro el que rompe el cascarón de lo que somos, nos fuerza a descubrir lo ya sido como pasado, y abrirnos a la novedad y al don del ser. El otro es, así, la alteridad que sustenta nuestra propia subjetividad, la forma de nuestra subjetividad. 
El otro tiene como rasgo fundamental la ausencia de patria común con nuestro yo, lo que le hace ser el extranjero, el indigente desde nuestros esquemas valorativos; un extranjero que perturba el "en nuestra casa" (Levinas, 1977: 63). La alteridad del otro me obliga a desinstalarme constantemente; es libre de las normas y convenciones de mi mundo, y fuerza mi propia libertad. El otro no se deja atrapar en las redes de nuestro pensamiento conceptual, no cabe en nuestras esquematizaciones de la realidad que rigen nuestro mundo; no se deja atrapar por nuestros conceptos, los trasciende y desmiente la seguridad con la que se afirman. Es más, si pretendiéramos conceptualizarlo y poseerlo, ya no sería otro, sino un elemento más del conjunto de todas las cosas que están a la mano, uno más de los conceptos de nuestro mundo; dejaría de ser otro, la posibilidad de nuestra propia libertad. Por eso, puede decir Levinas: "Proponemos llamar religión a la ligadura que se establece entre el Mismo y el Otro, sin construir una totalidad" (Levinas, 1977: 63).

Esta coincidencia entre el otro como alteridad y el otro como el extranjero se concreta cuando Levinas aborda el problema de la verdad, y lo relaciona íntimamente con el de la justicia (Levinas, 1977: 104). La exigencia de justicia es necesariamente la primera condición para la epistemología. La libertad siempre se inicia anulando el automatismo de nuestras respuestas, y preguntándonos: ¿es esto realmente como hasta ahora he supuesto? Es decir, podemos seguir siendo libres porque desconfiamos de nuestras interpretaciones del mundo, porque somos críticos con lo que hemos elaborado. Pero, al ser el otro el que me saca de mis pre-comprensiones, justificar nuestra libertad no es probar racionalmente la pertinencia de mi comportamiento, sino hacerlo justo con los otros (Levinas, 1977: 105). En el pensamiento occidental el interrogante radical de la ética no ha sido tanto si mi libertad es justa, sino si ha dado una respuesta adecuada a la realidad. La interpelación del sufrimiento del otro se arrinconaba en los sentimientos compasivos, en las experiencias no-racionales. Esto ha hecho que los gritos de los otros, que nuestra brutalidad ha provocado, nos lleguen amortiguados; que hayamos sido miopes ante el sufrimiento de otros seres humanos.

El cuestionamiento y la interpelación del otro sobre nuestra propia vida tiene un rango de primariedad radical, aun cuando tenemos una tentación constante de olvidarlo y constituirnos en el olvido del sufrimiento. El hecho de que no respondamos a esa interpelación no desmentirá la realidad que ha creado. Nuestra infidelidad, nuestras ceguera y sordera, no puede desmentir lo que somos en realidad, que se nos han dado ojos para ver y oídos para oír. Por eso, siempre hay una puerta abierta a la redención. Somos seres lábiles, constantemente desgarrados por la infidelidad; pero esa labilidad sólo se puede comprender en un ser 
abierto a una dignidad que lo supera. Nuestra actitud compasiva ante el otro en necesidad es condición necesaria para el surgimiento de la razón y la ética, fundamento árquico de nuestra propia intimidad personal, como apunta la Fratelli tutti.

\section{CONCLUSIÓN}

En este artículo he querido mostrar un camino por el que avanzar en la comprensión de la fraternidad humana como fundamento de nuestra dignidad. Ese camino abierto por la reflexión metafísica de Zubiri y Levinas nos muestra que son primariamente los otros los que sostienen nuestra dignidad. Dignidad personal y fraternidad humana vienen dadas de la mano. Esta intuición está presente en toda la experiencia cristiana; pero es Pablo de Tarso quien situó explícitamente la dignidad de la persona no en un comportamiento que buscara la perfección, ni en el cumplimiento de normas que identificara como miembros del pueblo elegido, sino en la relación con el Otro, con Jesucristo. La experiencia cristiana, como toda la fe bíblica, hace de nuestra actitud ante los más pobres la piedra de toque de nuestra relación con Dios y, por tanto, de nuestra salvación. La filosofía personalista del siglo XX - tomado este adjetivo de manera amplia - avanza en la comprensión de cómo los otros constituyen nuestra propia realidad humana y que son, también, forma de nuestra propia subjetividad. Desde esta comprensión ética y antropológica se manifiesta que el individualismo y el decisionismo éticos no se basan en la realidad de la persona. Y, por el contrario, que solo el comunitarismo personalista, y su esbozo de fraternidad, perfila el horizonte en el que podemos asumir quiénes somos y cómo ir realizándonos en nuestra propia verdad.

Como han observado algunos estudiosos, la encíclica Fratelli Tutti no se hace eco de la filosofía personalista del siglo XX, a la que muchos pensadores cristianos han hecho importantes contribuciones (Prieto Santana, 2020). Quizás siendo consciente de los diversos fundamentos racionales, metafísicos o antropológicos que se dan a esa realidad, ha preferido que seamos los profesores de filosofía los que pongamos de manifiesto la racionalidad intrínseca de su propuesta. El papa Francisco, consciente de que hay más de un camino para llegar a Roma, sabe que también hay más de un camino para acercarnos a la fraternidad que funda nuestra vida. En esta reflexión hemos intentado esbozar uno de ellos.

\section{REFERENCIAS}

Aristóteles (2008). Ética a Nicómaco. Madrid: Alianza. 
Álvarez-Cineira, D. (2016). Nuevas perspectivas sobre Pablo. Revista Caritas Veritatis, (1), 47-92.

Benedicto XVI (2008). Catequesis sobre san Pablo. Audiencia general miércoles 3 de septiembre. Disponible en https://www.vatican.va/content/benedictxvi/es/audiences/2008/documents/hf_ben-xvi_aud_20080903.html

Bornkamm, G. (1979). Pablo de Tarso. Salamanca: Sígueme.

Camus, A. (1985). El mito de Sísifo. Buenos Aires: Losada.

Castellón Martín, J. (2004). El rostro del otro y la experiencia profética. Algunas notas sobre Levinas. Isidorianum, 13(25), 257-278.

Ellacuría, I. (1981). El testamento de Sartre. Revista de Estudios Centroamericanos, 36(387-388), 43-50.

Fernández Ramos, F. (1999). Diccionario de San Pablo. Burgos: Monte Carmelo.

Francisco (2020). Carta encíclica Fratelli Tutti. Sobre la fraternidad y la amistad social. Disponible

en https://www.vatican.va/content/francesco/es/encyclicals/documents/pa pa-francesco_20201003_enciclica-fratelli-tutti.html

Guevara-Pereda, L. (2017). El discurso de Pablo en Atenas: el nacimiento del pensamiento occidental. Tesis de grado, Facultad de Filosofía, Universidad Panamericana, México. Disponible en https://scripta.up.edu.mx/bitstream/handle/20.500.12552/2409/159805. pdf? sequence $=1$ \&is Allowed $=\mathrm{y}$

Gilson, E. (2004). El Espiritu de la filosofía medieval. Madrid: Rialp.

Heimsoeth, H. (1990). Los seis grandes temas de la metafísica occidental. Madrid: Alianza.

Juan Pablo II (1991). Carta encíclica Centesimus annus: Disponible en https://www.vatican.va/content/john-paul-

ii/es/encyclicals/documents/hf_jp-ii_enc_01051991_centesimusannus.html

Lendon, J. E. (1997). Empire of Honour. The Art of Government in the Roman World. Oxford: Oxford University Press.

Levinas, E. (1977). Totalidad e infinito. Salamanca: Sígueme.

Pereira-Delgado, A. (2021). Tendencias actuales de los estudios paulinos. Vademécum para teólogos. Anthologica Annua, (65) (en edición).

Prieto Santana, M. D. (2020). Fratelli tutti: sobre el fundamento antropológico de la encíclica del Papa Francisco. Fronteras CTR, Revista de Ciencia, tecnología y religión, 7 de octubre. Disponible en https://blogs.comillas.edu/FronterasCTR/?p=5370

Rodríguez Duplá, L. (2016). Ética. Madrid: BAC.

Séneca (1986). Epistolas morales a Lucilio. Madrid: Gredos.

Stark, R. (2009). La expansión del cristianismo. Un estudio sociológico. Madrid: Trotta.

Tomillo Noguero, F. (2010). La hospitalidad en la antigua Grecia: de la Odisea a las Leyes. Homo Viator, Revista Hermenéutica del Viaje, la Hospitalidad y el Ocio, (1), 212-234.

Vidal, S. (2007). De Tarso a Roma. Santander: Sal Terrae. 
Vanni, U. (2006). Las Cartas de Pablo: el autor, las cartas, las enseñanzas. Buenos Aires: Claretiana.

Zubiri, X. (1986). Sobre el hombre. Madrid: Alianza. 